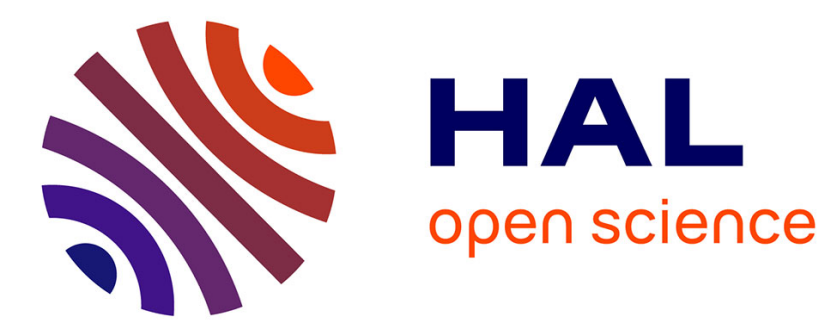

\title{
Structure and biological response of polymer/silica nanocomposites prepared by sol-gel technique
}

\author{
A. Vallés-Lluch, E. Costa, G. Gallego Ferrer, M. Monleón Pradas, M.
}

Salmerón-Sánchez

\section{To cite this version:}

A. Vallés-Lluch, E. Costa, G. Gallego Ferrer, M. Monleón Pradas, M. Salmerón-Sánchez. Structure and biological response of polymer/silica nanocomposites prepared by sol-gel technique. Composites Science and Technology, 2010, 70 (13), pp.1789. 10.1016/j.compscitech.2010.07.008 . hal-00681636

\section{HAL Id: hal-00681636 \\ https://hal.science/hal-00681636}

Submitted on 22 Mar 2012

HAL is a multi-disciplinary open access archive for the deposit and dissemination of scientific research documents, whether they are published or not. The documents may come from teaching and research institutions in France or abroad, or from public or private research centers.
L'archive ouverte pluridisciplinaire HAL, est destinée au dépôt et à la diffusion de documents scientifiques de niveau recherche, publiés ou non, émanant des établissements d'enseignement et de recherche français ou étrangers, des laboratoires publics ou privés. 


\section{Accepted Manuscript}

Structure and biological response of polymer/silica nanocomposites prepared by sol-gel technique

A. Vallés-Lluch, E. Costa, G. Gallego Ferrer, M. Monleón Pradas, M.

Salmerón-Sánchez

PII:

S0266-3538(10)00265-4

DOI:

10.1016/j.compscitech.2010.07.008

Reference:

CSTE 4762

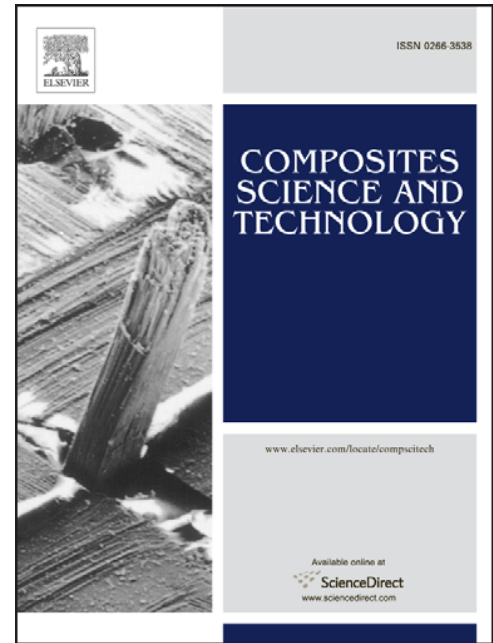

To appear in:

Composites Science and Technology

Received Date:

1 December 2009

Revised Date:

15 May 2010

Accepted Date:

9 July 2010

Please cite this article as: Vallés-Lluch, A., Costa, E., Ferrer, G.G., Pradas, M.M., Salmerón-Sánchez, M., Structure and biological response of polymer/silica nanocomposites prepared by sol-gel technique, Composites Science and Technology (2010), doi: 10.1016/j.compscitech.2010.07.008

This is a PDF file of an unedited manuscript that has been accepted for publication. As a service to our customers we are providing this early version of the manuscript. The manuscript will undergo copyediting, typesetting, and review of the resulting proof before it is published in its final form. Please note that during the production process errors may be discovered which could affect the content, and all legal disclaimers that apply to the journal pertain. 


\title{
Structure and biological response of polymer/silica nanocomposites prepared by sol-gel technique
}

\author{
A. Vallés-Lluch ${ }^{\mathrm{a}, \mathrm{b}}$, E. Costa ${ }^{\mathrm{a}}$, G. Gallego Ferrer ${ }^{\mathrm{a}, \mathrm{b}, \mathrm{c}}$, \\ M. Monleón Pradas ${ }^{\mathrm{a}, \mathrm{b}, \mathrm{c}}$, M. Salmerón-Sánchez ${ }^{\mathrm{a}, \mathrm{b}, \mathrm{c}^{*}}$ \\ ${ }^{a}$ Center for Biomaterials and Tissue Engineering, Universidad Politécnica de \\ Valencia, 46022 Valencia, Spain \\ ${ }^{b}$ Regenerative Medicine Unit, Centro de Investigación Príncipe Felipe, Autopista \\ del Saler 16, 46013 Valencia, Spain \\ ${ }^{c}$ CIBER de Bioingeniería, Biomateriales y Nanomedicina (CIBER-BBN), Valencia, \\ Spain \\ * corresponding author: masalsan@ fis.upv.es, tel +34 963877275, fax: +34 963877276
}

\begin{abstract}
Structure of $\mathrm{P}(\mathrm{EMA}-\mathrm{co}-\mathrm{HEA}) / \mathrm{SiO}_{2}$ nanocomposites with silica content in the range from 0 to $30 \%$ wt was correlated with cell behaviour on substrates of those compositions by making use of two different populations of primary human cells: articular cartilage chondrocytes and dental pulp cells. Substrates were prepared by the simultaneous copolymerization of the organic monomers and the sol-gel reaction of the silica precursor in different proportions, which led to weight fractions of the silica phase in the materials closely matching the stoichiometric ratios employed during the preparation, both in the bulk and at the material surface. The silica nanophase increases surface wettability and improves the mechanical properties of the base materials. Both chondrocytes and dental pulp cells were cultured on serum-coated nanocomposite substrates in the same conditions, but very different cellular responses were obtained. While chondrocytes adhered and proliferated, dental pulp cells formed viable aggregates weakly adhered on the sample that were viable up to 11 days. The results suggest that these sol-gel derived nancomposites may be used as culture surfaces maintaining the dental pulp cell phenotype in vitro.
\end{abstract}

Keywords: Nanocomposite, hybrid, acrylate, silica, cellular response 


\section{Introduction}

Polymer hydrogels stand out among synthetic materials used as biomaterials because of their good biocompatibility due, mainly, to their ability to absorb large amounts of water. However, they have poor mechanical properties and, as a consequence, they are in need of reinforcement. There are several routes to reinforce a polymer hydrogel, including the copolymerization with a hydrophobic component and the preparation of interpenetrating polymer networks [1,2]. A different strategy consists in the preparation of hybrid organic/inorganic nanocomposites, which include a silica phase obtained simultaneously with the polymer in a sol-gel process. [3].

Apart from reinforcement, there is a great need of providing bioactivity to surfaces in applications where good interaction between the synthetic material and the living tissues in mandatory. Since the discovery of the 45S5 Bioglass $®$ by Hench in 1971 [4], which appeared to strongly adhere to bone tissue, various kinds of ceramics such as $\mathrm{Na}_{2} \mathrm{O}$ $\mathrm{CaO}-\mathrm{SiO}_{2}-\mathrm{P}_{2} \mathrm{O}_{5}$ glasses, sintered hydroxyapatite and glass-ceramics containing apatite or wollastonite, are known to bond directly to living bone avoiding the formation of fibrous tissue [5-7]. Some of them or their derivatives are being clinically used in artificial middle-ear bone implants, artificial vertebrae, intervertebral discs, iliac bones, fillers in bone and maxillofacial defects or to fill the gaps around the implants, etc. and have inspired new bioactive materials with varied compositions and structures to fulfill different applications [8-13]. However, the use of bioactive glasses for the stimulated regeneration of tissues is limited by their poor mechanical properties, since their brittleness makes difficult their use in load-bearing applications.

One approach to combine bioactivity and enhanced mechanical properties in the same material is the preparation of organic/inorganic hybrids, in which the inorganic phase is incorporated into an organic polymeric matrix. This type of structural organization to a certain extent mimics the composition of mineralized tissues, where the hydroxyapatite 
(HAp) inorganic phase is dispersed in a collagen matrix with which it interacts at a molecular level yielding a natural composite. Various hybrid systems have been explored employing as inorganic phases bioactive glasses [15,16], HAp [17-19] or pure silica [25], in the form of particles or fibres. Porous scaffolds of hybrid composites mimicking natural bone structures have been prepared and investigated to serve as a support and guide new tissue in-growth and regeneration [20-23]. In the recent past many studies have been devoted to organic/inorganic nanocomposites with the aim of combining the properties of both phases at the nanoscale level. Polymer/silica nanocomposites have been prepared by physically mixing silica nanoparticles with polymers $[24,25]$ or by copolymerization of the organic polymers with surfacefunctionalized silica nanoparticles [26,27]. Various surface modification techniques have also been proposed aiming to enhance the bioactivity of polymer surfaces. These methods are based on the introduction of hydrophilic polar groups, such as phosphate, hydroxy groups, $\mathrm{Si}-\mathrm{OH}$ or $\mathrm{Ti}-\mathrm{OH}$, and carboxy and carboxylate groups, which have been found to be effective for apatite nucleation, onto more hydrophobic less bioactive substrates [28-30]. Nonetheless, the idea of nanohybridizing biocompatible polymers with silica by this simultaneous in situ sol-gel polymerization to improve their bioactivity is a very recent one. Few published works address it. Rhee et al. [28,29] polymerized poly(E-caprolactone) simultaneously via sol-gel with tetraethoxysilane (TEOS) as silica precursor and calcium nitrate tetrahydrate to dope the nanohybrid with calcium ions to facilitate the apatite nucleation. Costa et al. [30] polymerized poly(2hydroxyethyl methacrylate) by the same procedure with tetramethoxysilane (TMOS) as silica precursor and characterized the hydroxyapatite layer formed.

In previous works we addressed the structure, physicochemical properties and hydroxyapatite nucleation ability of poly(ethyl methacrylate-co-hydroxyethyl 
acrylate)/silica, $\mathrm{P}(\mathrm{EMA}-\mathrm{co}-\mathrm{HEA}) / \mathrm{SiO}_{2}$, nanohybrids with silica contents comprised between 0 and $30 \%$ wt as potential candidates for the synthetic matrix of scaffolds for bone or dentin regeneration $[3,31,32]$. Here we analyze the effect of the presence of silica on the in vitro biological performance of this series of substrates making use of two different human primary cells: articular cartilage chondrocytes and dental pulp cells. This work is a first attempt to understand the interaction of these specific sol-gel derived nanocomposites with human cells in vitro. We employed two cell populations stemming from human tissues with very different properties and lineage. Chondrocytes are mature cells which are in need of adequate substrates for their in vitro expansion while maintaining their phenotype; dental pulp cells are immature, multipotent cells able to differentiate to osteoblasts. Our results show that sol-gel derived nanocomposites might be useful for maintaining the characteristic dental pulp phenotype in vitro, minimizing interactions with the artificial substrate while keeping the cell population viable.

\section{Materials and methods}

Synthesis of $\mathrm{P}(\mathrm{EMA}-\mathrm{co}-\mathrm{HEA}) / \mathrm{SiO}_{2}$ nanohybrids

Nanocomposites of poly(ethyl methacrylate-co-hydroxyethyl acrylate), p(EMA-coHEA), with fixed EMA/HEA weight ratio of 70/30 \%wt and with varying proportions of silica, $\mathrm{SiO}_{2}: 0,5,10,15,20$ and $30 \% \mathrm{wt}$, were obtained in the form of sheets of 0.8 $\mathrm{mm}$ in thickness similarly as in [3]. Briefly, the procedure consisted in preparing an organic mixture of the organic monomers ethyl methacrylate, EMA (99\%, Aldrich), and hydroxyethyl acrylate, HEA (96\%, Aldrich), with a $0.5 \%$ wt of ethylene glycol dimethacrylate, EGDMA (98\%, Aldrich), as crosslinking agent and a $2 \%$ wt of benzoyl peroxide, BPO (97\%, Fluka), as thermal initiator, relative to monomer weight. 
Separately, tetraethoxysilane, TEOS, was mixed with distilled water and hydrochloric acid (37\%, Aldrich) in the molar ratio 1:2:0.0185, respectively (inorganic mixture). After $30 \mathrm{~min}$ of separate stirring, both solutions were mixed, stirred for another $30 \mathrm{~min}$ and injected into glass moulds. The hybrid mixture was polymerized in an oven at $60^{\circ} \mathrm{C}$ for $21 \mathrm{~h}$ and post-polymerized at $90^{\circ} \mathrm{C}$ for $18 \mathrm{~h}$, rinsed in boiling distilled water/ethanol mixture 50/50 \%vol for 24 hours to eliminate monomer residues and finally dried in a vacuum desiccator at $80^{\circ} \mathrm{C}$ until constant weight. Materials with silica contents of 0,5 , 10, 15, 20 and $30 \%$ wt were obtained by calculating the (EMA+HEA)/TEOS ratios assuming that the sol-gel reaction was complete. Hereafter, the hybrids will be referred to as $\mathrm{Hx}, \mathrm{x}$ being the percentage of silica. Besides, poly(ethyl methacrylate), PEMA, and poly(hydroxyethyl acrylate), PHEA, homopolymers were prepared following the same procedure as reference systems.

Fourier-transform infrared spectroscopy (FTIR) analyses

Fourier-transform infrared (FTIR) spectra were collected in a Thermo Nicolet Nexus FTIR spectrometer (Thermo Fischer Scientific Inc., Waltham, MA, USA), in the attenuated total reflection mode (ATR), to elucidate the surface compositions. The spectra resulted from averages of 128 scans at $4 \mathrm{~cm}^{-1}$ resolution, between 650 and 4000 $\mathrm{cm}^{-1}$

Quantification of $\mathrm{SiO}_{2}$ by energy dispersive x-ray spectroscopy (EDS)

The percentage of silica at the surfaces and in the interior of the nanohybrids was quantified by energy dispersive x-ray spectroscopy (EDS) in an Oxford Instruments spectrometer, attached to a JSM-6300 scanning electron microscope (JEOL Ltd., 
Tokyo, Japan). Exterior and inner (fracture) surfaces were analyzed. Samples were previously sputter-coated with carbon under vacuum. Spectra were taken at $10 \mathrm{kV}$ of acceleration voltage and $15 \mathrm{~mm}$ of working distance. Silicon was employed as optimization standard.

\section{Contact angle measurements}

In order to determine the surface wettability of the different substrates, contact angle measurements were conducted in air atmosphere with the sessile drop method, employing water (extra pure, Scharlau) as drop liquid. A Dataphysics OCA instrument (DataPhysics Instruments GmbH, Filderstadt, Germany) was used for this purpose. Glass Pasteur pipettes were employed as droppers. A minimum of 10 drops of water was analyzed for each composition.

\section{Compression tests}

Mechanical compression tests were performed in a Seiko TMA/SS6000 device (Seiko Instruments Inc., Chiba, Japan), from 0.05 to $150 \mathrm{~g}$ at $10 \mathrm{gmin}^{-1}$, at room temperature. Specimens were disk-shaped ( $3 \mathrm{~mm}$ in diameter, $0.8 \mathrm{~mm}$-thick) and each composition set consisted of five replicas.

\section{Chondrocytes}

Human articular cartilage from the knee of a patient undergoing total knee arthroplasty was processed for chondrocyte isolation. Briefly, the cartilage tissue was aseptically dissected from the joint, minced, and washed with Dulbecco's modified Eagle's medium (DMEM, Life Technologies). Then, the cartilage was incubated for $30 \mathrm{~min}$ with a $0.5 \mathrm{mg} / \mathrm{mL}$ hyaluronidase (Sigma-Aldrich) solution and for $1 \mathrm{~h}$ with a $1 \mathrm{mg} / \mathrm{mL}$ 
pronase (Merck) solution in a shaking water bath at $37^{\circ} \mathrm{C}$. After that, the cartilage fragments were washed with DMEM and incubated with a $0.5 \mathrm{mg} / \mathrm{mL}$ collagenase-IA (Sigma-Aldrich) solution in a shaking water bath at $37^{\circ} \mathrm{C}$ overnight. The resulting cell suspension was filtered with a $70 \mu \mathrm{m}$ cell strainer (BD Biosciences) to remove any undigested tissue and collagenase was rinsed off with DMEM containing $10 \%$ FBS (Invitrogen SA). Finally, the cell suspension obtained was transferred in $15 \mathrm{~mL}$ DMEM supplemented with $10 \%$ FBS and $50 \mu \mathrm{g} / \mathrm{mL}$ ascorbic acid (Sigma-Aldrich) to a $75 \mathrm{~cm}^{2}$ tissue culture flask (Nunc) and maintained at $37^{\circ} \mathrm{C}$, in a humidified atmosphere under $5 \% \mathrm{CO}_{2}$. The culture medium was replaced every 2 days and cells were allowed to grow until subconfluence. Then, the cells were harvested by trypsinisation and counted with a hemacytometer for the experiment.

\section{Dental pulp cells}

Human dental pulp cells were isolated from third molar teeth extracted due to odontological reasons from healthy patients. First, pulp was extracted and washed with Hank's balanced solution (Gibco-Invitrogen, USA) supplemented with penicillin/streptomycin (100 U/ml and $100 \mu \mathrm{g} / \mathrm{ml}$ respectively, Gibco-Invitrogen). Pulp was minced in small fragments and incubated with a $2 \mathrm{mg} / \mathrm{mL}$ collagenase-IA (SigmaAldrich) solution in a shaking water bath at $37^{\circ} \mathrm{C}$ for $90 \mathrm{~min}$. Cellular suspension was centrifuged (400 g for $7 \mathrm{~min}$ ) and the resulting pellet was seeded on a to a $75 \mathrm{~cm}^{2}$ tissue culture flask (Nunc) in DMEM containing 10\% FBS and antibiotics and maintained at $37^{\circ} \mathrm{C}$, in a humidified atmosphere under $5 \% \mathrm{CO}_{2}$. The culture medium was replaced every 2 days and cells were allowed to grow until subconfluence. Then, the cells were harvested by trypsinisation and counted with a hemacytometer for the experiment. 


\section{Cell culture}

Films pre-sterilized with $25 \mathrm{kGy}$ gamma radiation were placed in a 96-well tissue culture plate and were soaked in culture medium for $72 \mathrm{~h}$ before cell seeding. Then, 40 $\mu \mathrm{L}\left(10^{4}\right.$ cells $)$ of the cell dispersion were placed onto the polymer films and were incubated at $37^{\circ} \mathrm{C}$ under $5 \% \mathrm{CO}_{2}$ condition for $1 \mathrm{~h}$. After this time, $600 \mu \mathrm{L}$ of fresh medium were added to each well. Samples were maintained at $37^{\circ} \mathrm{C}$, in a humidified atmosphere under $5 \% \mathrm{CO}_{2}$ for 10 days. The culture medium used was DMEM supplemented with $10 \% \mathrm{FBS}$ and $50 \mu \mathrm{g} / \mathrm{mL}$ ascorbic acid and it was renewed every $2-3$ days. Contrast phase light microscopy was carried out to observe morphological changes in cell shape after different time cultures. Neutral red staining was employed as a vital staining. Each experiment was performed in triplicate and TCPS served as the control substrate.

\section{Results and discussion}

Figure 1 shows the FTIR spectra of the nanocomposites and both homopolymers. The $\mathrm{CH}_{\mathrm{x}}$ asymmetric and symmetric stretching peaks appear at 2962 and $2888 \mathrm{~cm}^{-1}$, respectively, in all spectra, and the broad band between 3700 and $3100 \mathrm{~cm}^{-1}$, as well as the shoulder at $1650 \mathrm{~cm}^{-1}$, characteristic of the hydroxy groups, only appears in the PHEA spectrum (data not shown). The well-defined $\mathrm{C}=\mathrm{O}$ stretching peak $\left(1700 \mathrm{~cm}^{-1}\right)$ decreases with the percentage of silica. Between 1700 and $650 \mathrm{~cm}^{-1}$ the FTIR curves show the complex spectrum of the copolymer blurring the silica fingerprint region. The intensity of the peaks at $1100 \mathrm{~cm}^{-1}$ and $800 \mathrm{~cm}^{-1}$ (Si-O-Si asymmetric and symmetric stretching, respectively) and $950 \mathrm{~cm}^{-1}$ (Si-OH stretching), characteristic of the silica phase $[28,29]$, increases with the silica content. No evidence of hybrid Si-O-C bonds from heterocondensation reactions can be found by FTIR, because their characteristic 
peak (1120-1080 and $\left.836 \mathrm{~cm}^{-1}\right)$ [29] overlaps the absorption interval of the Si-O-Si bonds. The absence of the broad band characteristic of the $\mathrm{OH}$ groups of the silanols or the $\mathrm{OH}$ vibrations of HEA can be explained by an imperfect contact of the sample and the measuring device, caused by the rigidity of the samples at room temperature. This band appeared only after immersion of the samples in water to render them softer (data not shown).

The experimental silica contents, $\mathrm{SiO}_{2}$ EDS, listed in Table 1 were calculated from the silicon average contents obtained by EDS, making use of the silica and silicon molar masses and neglecting the amount of hydrogen in the copolymer and in the silanol groups, undetectable by this technique and the carbon coating of the samples for performing the EDS measurements. The surface and bulk silica percentages are very similar and correlate quite well with the nominal silica contents of the hybrids, despite the considerations concerning the detection of hydrogen and carbon. This is an important issue since the biological media will interact with the components on the surface of the sample. The larger standard deviations of the silica contents obtained in the bulk are due to the limitations of this technique when working with fractured samples of variable height. Both the FTIR spectra and the silica quantifications by EDS corroborate that TEOS was efficiently hydrolyzed and condensed to silica during the sol-gel process, and silica was found to be homogeneously distributed throughout the polymeric matrix both in the bulk and at the surface.

The average water contact angles, $\theta_{w}$, are also listed in Table 1 . The water contact angle of the H05 surface is identical to that of the copolymer, lying between those of the homopolymers. It then decreases for intermediate silica contents (10-20\%wt) and increases again for the $\mathrm{H} 30$ surface, reaching a value close to that of the copolymer. The compressive elastic moduli, $E$, were obtained from the initial slopes of the stress-strain 
curves, and are also listed in Table 1. The modulus of the copolymer lies between those of the homopolymers, and maintains similar values up to $15 \%$ wt of silica, from where it starts increasing up to a value similar to that of PEMA for the H30 composite.

As explained in a previous work [31], different inorganic phase morphologies are obtained within the copolymeric matrix depending on the silica content. Below a 15 $\%$ wt of silica the inorganic phase is uniformly dispersed in the nanocomposites as porous nanoparticles which form larger aggregates leaving spaces of tens of nanometers. Higher silica contents produce silica networks which percolate and eventually extend continuously throughout the samples, totally interpenetrated with the organic network. These different phase morphologies influence the physicochemical properties of the surfaces. The number of free $\mathrm{Si}-\mathrm{OH}$ groups is larger the larger the boundary interface of the silica phase, and thus decreases as percolation occurs and with the development of the continuous silica network. This is reflected in the wettability of the nanocomposites with high silica contents. Besides, the reinforcing effect of the interpenetrated silica phase is observed in the increase of the compressive elastic modulus of the nanohybrids.

Cells respond to different kinds of surface parameters: chemical, topographical and mechanical, through the intermediacy of extracellular matrix (ECM) proteins. Here we investigated the role of increasing amounts of silica of the material surface on the biological performance of the substrate. Cellular behavior at the biomaterials interface can be understood in terms of the natural adhesive interaction of cells with the ECM [33]. Cells do not interact directly with foreign materials, but they attach to the adsorbed layer of proteins on the material surface, such as fibronectin $(\mathrm{FN})$, vitronectin $(\mathrm{VN})$, fibrinogen $(\mathrm{FNG})$, representing the so called soluble matrix proteins in the biological fluids [33]. Cells recognize these matrix proteins via integrins - a family of cell surface 
receptors - that provide trans-membrane links between the ECM and the actin cytoskeleton [34]. When integrins are occupied they cluster and develop focal adhesion complexes that actually anchor the cells to the surface and trigger the subsequent cellular response [34]. Thus, the cell-material interaction is a complex process consisting of early events, such as adsorption of proteins, followed by cell adhesion and spreading, and later events, related to cell growth, differentiation, matrix deposition and cell function.

Figure 2 shows human articular chondrocytes after 1 day of culture on the different substrates. Cells are well spread and distributed throughout the surface of the samples independently of the amount of silica in the material (from 5 to $30 \%$ ). The fraction of the surface covered by cells is lower for the homopolymers (both PEMA and PHEA) than for the 70/30 \%wt copolymer. This family of polymers represents a set of materials with very different mechanical properties (see table 1) that support chondrocyte expansion. From an applied perspective, the incorporation of silica within the polymer matrix represents a way of matching the properties of the material to those of articular cartilage; since the stiffness of the sample is known to influence the cell-material interaction [35-37], it is important in our case that this increased stiffness does not modify the biological performance of the substrate. Chondrocytes remain covering the surface of the material and start growing in layers (cell on cell) up to 10 days on culture (results not shown, microscopy images are similar to those shown in Figure 2 where a confluence monolayer is already formed).

The situation is completely different when the same family of materials is seeded with human dental pulp cells (Figure 3). After two days of culture the cells are spread on PEMA, PHEA and the 70/30 \%wt copolymer. However, addition of silica to the system leads to a complete modification of the cell-material interaction, which changes 
dramatically as the amount of silica in the system increases. Cells tend to form clusters which adhere weakly to the surface of the material, in a growing number as the silica content increases. This is in agreement with the results found by Cousins et al. [38] with L929 murine fibroblasts seeded on silica nanoparticulate coatings, which showed a weakly adhered rounded conformation in comparison with the same cells seeded on a plain glass surface, with spread flattened morphology. These authors hypothesized that the nanostructure of silica governs the serum proteins-substrate interactions, leading to localized focal adhesion sites, and thus to weakly adhered rounded cells. In our case, the presence of silica on the material substrate implies the presence of a higher concentration of $\mathrm{OH}$ groups on the material and a slightly negatively charged surface that leads to a more wettable surface (table 1).

After 5 days of culture the cells remained clustered on the compositions with the lower content of silica $(5,10$ and $15 \% \mathrm{wt})$ while good adhesion and proliferation occurred on the samples with 20 and $30 \%$ wt silica (Figure 4). This behavior was previously found on TEOS based chitosan/silica membranes seeded with fibroblast-like cells. Cell growth rate, density and adhesion strength were lower for hybrid materials than for pure chitosan for lower silica contents (below $20 \%$ ), but similar or even increased values were obtained for a $50 \%$ wt inorganic content [39].

The pulp cells are shown to be viable after 5 days on the material as revealed by neutral red staining for the cell clusters (Figure 5). Besides, when these cells are collected from the nanocomposites and seeded again on a standard substrate they acquire the typical fibroblast-like morphology (Figure 5). This peculiar cell-material interaction behavior has interesting consequences for tissue engineering applications requiring phenotype maintenance. 
It is interesting to stress that the same nanocomposite materials, coated with the same solution of proteins (FBS in our case, that consists mainly of fibronectin and vitronectin), has a very different cell response depending on the cell type seeded, which reveals the specificity of the cell-material interaction. It is known that human chondrocytes tend to spread on material surfaces and adopt an extended morphology as a consequence of the production of collagen and expression of the $\alpha_{2} \beta_{1}$ integrin that mediates interaction with this protein [40]. However, dental pulp cells are in need of fibronectin and vitronectin adsorption on this set of substrates to adhere via the $\alpha_{5} \beta_{1}$ or $\alpha_{v} \beta_{3}$ receptors [41] which does not happen when silica is dispersed on the material surface due to conformational changes of fibronectin after adsorption on silica, reducing the availability of cell-binding domains [42].

\section{Conclusions}

Polymer/silica nanocomposites were prepared following a sol-gel process that leads to a material morphology of interpenetrated phases with controlled known concentration of silica both in the bulk and at the surface of the hybrid system. The incorporation of silica improves the mechanical properties of the polymer system and may influence the cellular response. Chondrocytes and dental pulp cells are both viable on the hybrid surfaces, but major differences are found between both cell types: chondrocytes are able to adhere and proliferate independently of the silica content of the surface, whereas dental pulp cells adhere only weakly and form clusters of cells that remain stable and viable up to 11 days.

\section{Acknowledgements}

Financial support of the Spanish government through project MAT2009-14440-C02-01 is kindly acknowledged. CIBER-BBN is an initiative funded by the VI National 
R\&D\&i Plan 2008-2011, Iniciativa Ingenio 2010, Consolider Program, CIBER Actions and financed by the Instituto de Salud Carlos III with assistance from the European Regional Development Fund. This work was supported by funds for research in the field of Regenerative Medicine through the collaboration agreement from the Conselleria de Sanidad (Generalitat Valenciana), and the Instituto de Salud Carlos III.

\section{References}

1. Salmerón Sánchez M, Gallego Ferrer G, Monleón Pradas M, Gómez Ribelles JL. Influence of the hydrophobic phase on the thermal transitions of water sorbed in a polymer hydrogel based on interpenetration of a hydrophilic and a hydrophobic polymer network. Macromolecules 2003; 36: 860.

2. Salmerón Sánchez M, Brígido Diego R, Ianazzo S, Monleón Pradas M, Gómez Ribelles JL. The structure of poly(ethyl acrylate-co-hydroxyethyl methacrylate) copolymer networks by segmental dynamics studies based on structural relaxation experiments. Polymer 2004; 45: 2349.

3. Rodríguez Hernández JC, Monleón Pradas M, Gómez Ribelles JL. Properties of poly(2-hydroxyethyl acrylate)-silica nanocomposites obtained by the sol-gel technique. J Non Cryst Sol 2008; 354: 1900.

4. Hench LL. The story of Bioglass. J Mater Sci: Mater Med 2006; 17: 967-978.

5. Ben-Nissan B, Ylänen HO. Bioactive glasses and glass ceramics. In: Akay M, ed. Wiley Encyclopedia of Biomedical Engineering. New Jersey: John Wiley \& Sons, 2006. p. 354-366.

6. Kokubo T. Bioactivity of glasses and glass-ceramics. In: Ducheyne P, Kokubo T, Blitterswijk CA, eds. Bone-bonding Biomaterials. Leidendorp: Reed Healthcare Communications, 1992: pp. 31-46.

7. Hench LL, Kokubo T. In: Black J, Hastings G, ed. Handbook of Biomaterials Properties. Chapman \& Hall, London, 1998: p. 355.

8. Kokubo T, Takadama H. How useful is SBF in predicting in vivo bone bioactivity? Biomaterials 2006; 27: 2907. 
9. Ohtsuki C, Kokubo T, Yamamuro T. Mechanism of apatite formation on $\mathrm{CaO}-\mathrm{SiO}_{2}$ $\mathrm{P}_{2} \mathrm{O}_{5}$ glasses in a simulated body fluid. J Non-Cryst Solids 1992; 143: 84.

10. Hench LL. Bioceramics. J Am Ceram Soc 1998; 81: 1705.

11. Zhang K, Yan H, Bell DC, Stein A, Francis LF. Effects of materials parameters on mineralization and degradation of sol-gel bioactive glasses with 3D-ordered macroporous structures. J Biomed Mater Res: A 2003; 66: 860.

12. Jones JR, Ehrenfried LM, Hench LL. Optimising bioactive glass scaffolds for bone tissue engineering. Biomaterials 2006; 27: 964.

13. Kim HM, Himeno T, Kawashita M, Kokubo T, Nakamura T. The mechanism of biomineralization of bone-like apatite on synthetic hydroxyapatite: an in vitro assessment. J R Soc Interface 2004; 1: 17.

14. Oréfice R, Clark A, West J, Brennan A, Hench L. Processing, properties, and in vitro bioactivity of polysulfone-bioactive glass composites. J Biomed Mater Res: A 2007; 80: 565.

15. Fang L, Leng Y, Gao P. Processing of hydroxyapatite reinforced ultrahigh molecular weight polyethylene for biomedical applications. Biomaterials 2005; 26: 3471 .

16. Li Z, Yubao L, Aiping Y, Xuelin P, Xuejiang W, Xiang Z. Preparation and in vitro investigation of chitosan/nano-hydroxyapatite composite used as bone substitute materials. J Mater Sci: Mater Med 2005; 16: 213.

17. Jie W, Yubao L. Tissue engineering scaffold material of nano-apatite crystals and polyamide composite. Eur Polym J 2004; 40: 509.

18. Eglin D, Ali SAM, Perry CC. Comparative study of the in vitro apatite-forming ability of poly( $\varepsilon$-caprolactone-silica sol-gels using three osteoconductivity tests (static, dynamic, and alternate soaking process). J Biomed Mater Res: A 2004; 69: 718.

19. Zhao L, Chang J. Preparation and characterization of macroporous chitosan/wollastonite composite scaffolds for tissue engineering. J Mater Sci: Mater Med 2004; 15: 625.

20. Meretoja VV, Helminen AO, Korventausta JJ, Haapa-aho V, Seppälä, JV, Närhi TO. Crosslinked poly( $\varepsilon$-caprolactone/D,L-lactide)/bioactive glass composite scaffolds for bone tissue engineering. J Biomed Mater Res: A 2006; 77: 261. 
21. Rezwan K, Chen QZ, Blaker JJ, Boccaccini AR. Biodegradable and bioactive porous polymer/inorganic composite scaffolds for bone tissue engineering. Biomaterials 2006; 27: 3413.

22. Huang SL, Chin WK, Yang WP. Structural characteristics and properties of silica/poly(2-hydroxyethyl methacrylate) (PHEMA) nanocomposites prepared by mixing colloidal silica or tetraethyloxysilane (TEOS) with PHEMA. Polymer 2005; 46: 1865.

23. Hajji P, David L, Gerard JF, Pascault JP, Vigier G. Synthesis, structure and morphology of polymer-silica hybrid nanocomposites based on hydroxyethyl methacrylate. J Polym Sci: Polym Phys 1999; 37: 3172.

24. Liu YL, Hsu CY, Hsu KY. Poly(methylmethacrylate)-silica nanocomposites films from surface-functionalized silica nanoparticles. Polymer 2005; 46: 1851.

25. Kawai T, Ohtsuki C, Kamitakahara M, Hosoya K, Tanihara M, Miyazaki T, Sakaguchi Y, Konagaya S. In vitro apatite formation on polyamide containing groups modified with silanol groups. J Mater Sci: Mater Med 2007; 18: 1037.

26. Oyane A, Minoda M, Miyamoto T, Takahashi R, Nakanishi K, Kim HM, Kokubo T, Nakamura T. Apatite formation on ethylene-vinyl alcohol cpopolymer modified with silanol groups. J Biomed Mater Res 1999; 47: 367.

27. Kawashita AM, Nakao M, Minoda M, Kim HM, Beppu T, Miyamoto T, Kokubo T, Nakamura T. Apatite-forming ability of carboxyl group-containing polymer gels in a simulated body fluid. Biomaterials 2003; 24: 2477.

28. Rhee SH, Choi JY, Kim HM. Preparation of a bioactive and degradable poly( $\varepsilon$ caprolactone)/silica hybrid through a sol-gel method. Biomaterials 2002; 23: 4915.

29. Rhee SH. Effect of molecular weight of poly(e-caprolactone) on interpenetrating network structure, apatite-forming ability, and degradability of poly $(\varepsilon-$ caprolactone)/silica nano-hybrid materials. Biomaterials 2003; 24: 1721.

30. Costa ROR, Pereira MM, Lameiras FS, Vasconcelos WL. Apatite formation on poly(2-hydroxyethyl methacrylate)-silica hybrids prepared by sol-gel process. J Mater Sci: Mater Med 2005; 16: 927.

31. Vallés-Lluch A, Gallego Ferrer G, Monleón Pradas M. Biomimetic apatite coating on $\mathrm{P}(\mathrm{EMA}-\mathrm{co}$-HEA)/SiO 2 nanocomposites. Polymer 2009; 50: 2874. 
32. Vallés-Lluch A, Gallego Ferrer G, Monleón Pradas M. Surface modification of $\mathrm{P}(\mathrm{EMA}-\mathrm{co}-\mathrm{HEA}) / \mathrm{SiO}_{2}$ nanohybrids for faster hydroxyapatite deposition in simulated body fluid. Colloid Surface B 2009; 70: 218.

33. Spie J. Tissue engineering and reparative medicine. Ann NY Acad Sci 2002; 961: 1.

34. Hynes RO. Integrins: bidirectional, allosteric signaling machines. Cell 2002; 110: 673.

35. Pelham JR, Wang YL. Cell locomotion and focal adhesions are regulated by substrate flexibility. Proc Natl Acad Sci USA 1997; 94: 13661.

36. Genes NG, Rowley JA, Mooney DJ, Bonassar LJ. Effect of substrate mechanics on chondrocyte adhesion to modified alginate surfaces. Arch Biochem Biophys 2004; 422 : 161.

37. Ryan PL, Foty RA, Kohn J, Steinberg MS. Tissue Spreading on implantable substrates is a competitive outcome of cell-cell vs. Cell-substratum sensivity. Proc Natl Acad Sci 2001; 98: 4323.

38. Cousins BG, Doherty PJ, Williams RL, Fink J, Garvey MJ. The effect of silica nanoparticulate coatings on cellular response. J Mater Sci: Mater Med 2004; 15: 355.

39. Coradin T, Allouche J, Boissière M, Livage J. Sol-Gel Biopolymer/Silica Nanocomposites in Biotechnology. Curr Nanosci 2006; 2: 219.

40. Brodkin KR, Garcia AJ, Levenston ME. Chondrocyte phenotype on different extracellular matrix monolayers. Biomaterials 2005; 25: 5929.

41. Zhu Q, Safavi KE, Spangberg LSW. Integrin expression in human dental pulp cells and their role in cell attachment on extracellular matrix proteins. J Endodontics 1998; 24: 641 .

42. Lord MS, Cousins BG, Doherty PJ, Whitelock JM, Simmons A, Williams RL, Milthorpe BK. The effect of silica nanoparticle coatings on serum protein adsorption and cellular response. Biomaterials 2006; 27: 4856. 


\section{Captions to Figures}

Figure 1. FTIR spectra of the different samples, in the $650-1850 \mathrm{~cm}^{-1}$ region.

Figure 2. Phase light contrast microscopy images of human articular chondrocytes on the different substrates after 1 day of culture. (a) PEMA, (b) PHEA, (c) P(EMA-coHEA) 70/30 \% wt copolymer. Nanohybrids with increasing amount of $\mathrm{SiO}_{2}$ (d) $5 \%$, (e) $10 \%$, (f) $15 \%$, (h) $20 \%$, (i) $30 \%$. Last image (j) represents control TCPS.

Figure 3. Phase light contrast microscopy images of dental pulp cells on the different substrates after 2 day of culture. (a) PEMA, (b) PHEA, (c) P(EMA-co-HEA) 70/30 \%wt copolymer. Nanohybrids with increasing amount of $\mathrm{SiO}_{2}$ (d) $5 \%$, (e) $10 \%$, (f) $15 \%$, (h) 20\%, (i) 30\%. Last image (j) represents control TCPS.

Figure 4. Phase light contrast microscopy images of pulp cells on the different substrates after 5 day of culture. (a) PEMA, (b) PHEA, (c) P(EMA-co-HEA) 70/30 \% wt copolymer. Nanohybrids with increasing amount of $\mathrm{SiO}_{2}$ (d) $5 \%$, (e) $10 \%$, (f) $15 \%$, (h) $20 \%$, (i) $30 \%$. Last image (j) represents control TCPS.

Figure 5. Phase light contrast microscopy images of human dental pulp cells on the nanocomposites. (left) 10 culture days on TCPS after culture for 4 days on the substrate with $15 \%$ wt $\mathrm{SiO}_{2}$. (right) Neutral red staining shows cell viability on $\mathrm{H} 05$ after 8 days. 
Table 1. Average $\mathrm{SiO}_{2}$ contents obtained by EDS, $\mathrm{SiO}_{2}{ }_{E D S}$, on the surface and in the bulk, water contact angles, $\theta_{w}$, and compressive elastic moduli, $E$.

\begin{tabular}{lcccr}
\hline \multirow{2}{*}{ Sample } & \multicolumn{2}{c}{$\mathrm{SiO}_{2}$ EDS $(\%)$} & \multirow{2}{*}{$\boldsymbol{\theta}_{w}\left({ }^{\mathbf{o}}\right)$} & \multicolumn{1}{c}{$\boldsymbol{E}(\mathbf{G P a})$} \\
\cline { 2 - 4 } & surface & bulk & & \\
\hline PEMA & - & - & $82.6 \pm 1.6$ & $4.2 \pm 0.1$ \\
PHEA & - & - & $96.1 \pm 3.9$ & $0.14 \pm 0.03$ \\
H00 & - & - & $91.8 \pm 2.3$ & $2.6 \pm 0.2$ \\
H05 & $5.18 \pm 1.06$ & $5.60 \pm 4.00$ & $92.0 \pm 1.6$ & $2.7 \pm 0.3$ \\
H10 & $9.06 \pm 0.21$ & $8.42 \pm 0.61$ & $80.1 \pm 2.9$ & $2.8 \pm 0.3$ \\
H15 & $15.09 \pm 0.27$ & $15.33 \pm 3.12$ & $76.5 \pm 1.4$ & $2.9 \pm 0.1$ \\
H20 & $21.21 \pm 0.61$ & $22.51 \pm 0.95$ & $76.8 \pm 4.1$ & $3.3 \pm 0.2$ \\
H30 & $28.45 \pm 0.58$ & $24.87 \pm 3.60$ & $90.5 \pm 2.2$ & $3.9 \pm 0.4$ \\
\hline
\end{tabular}


Figure 1

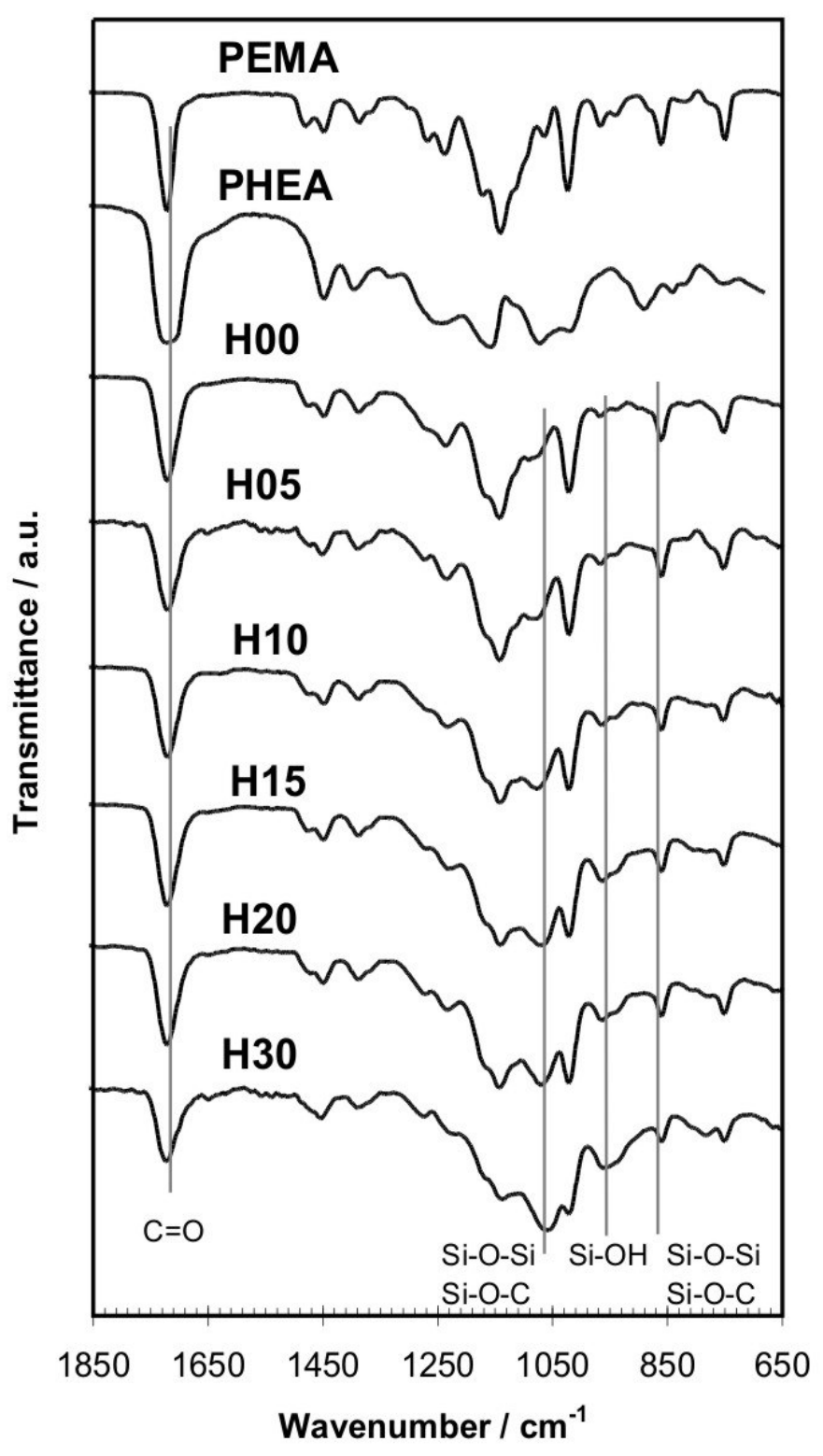


Figure 2
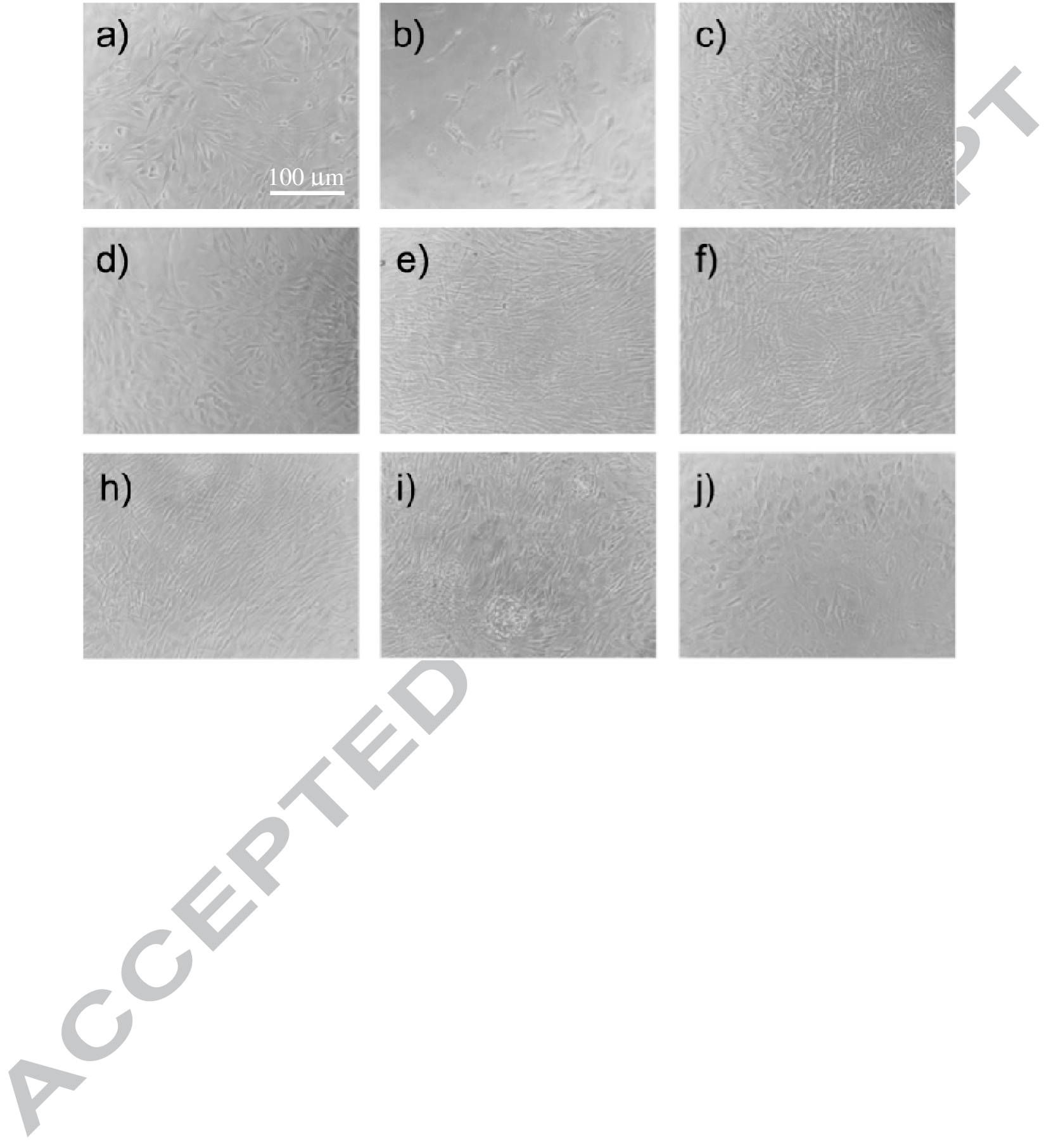
Figure 3
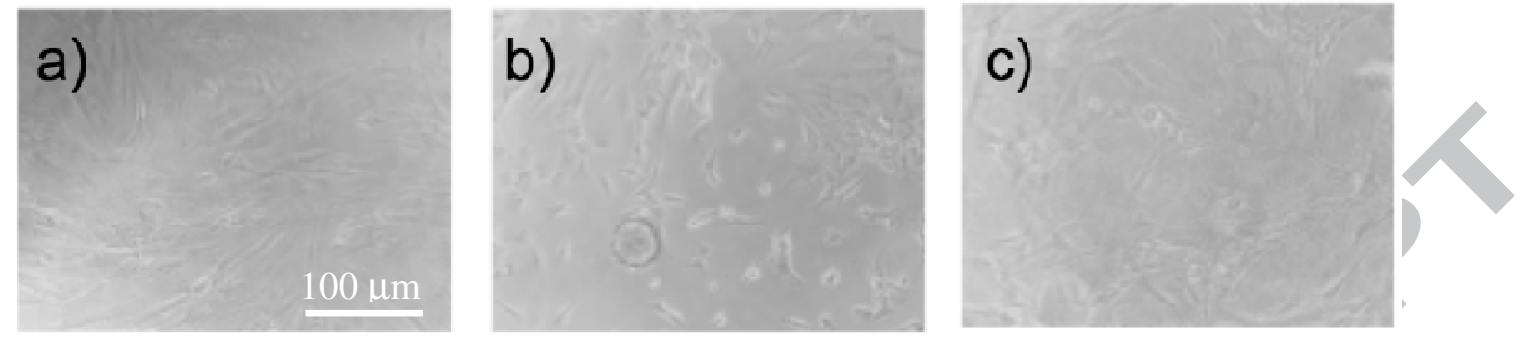

d)
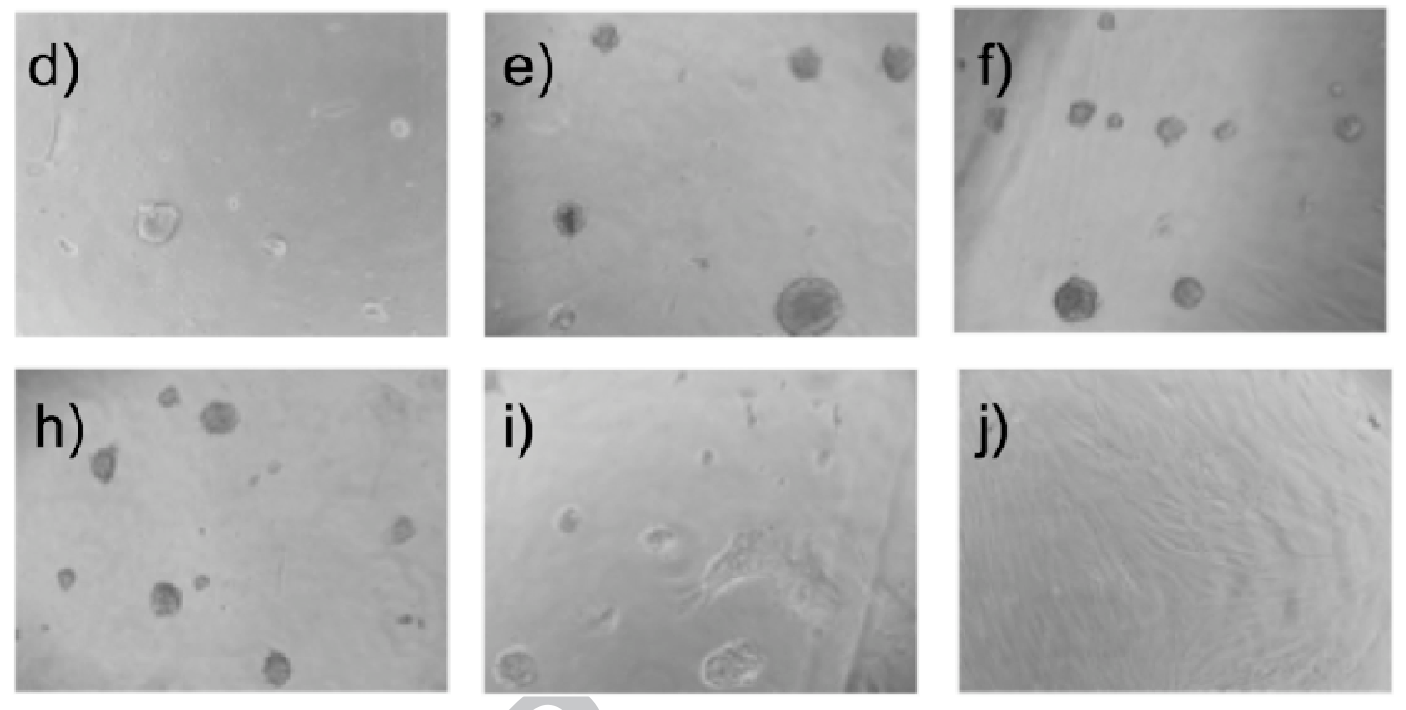
Figure 4
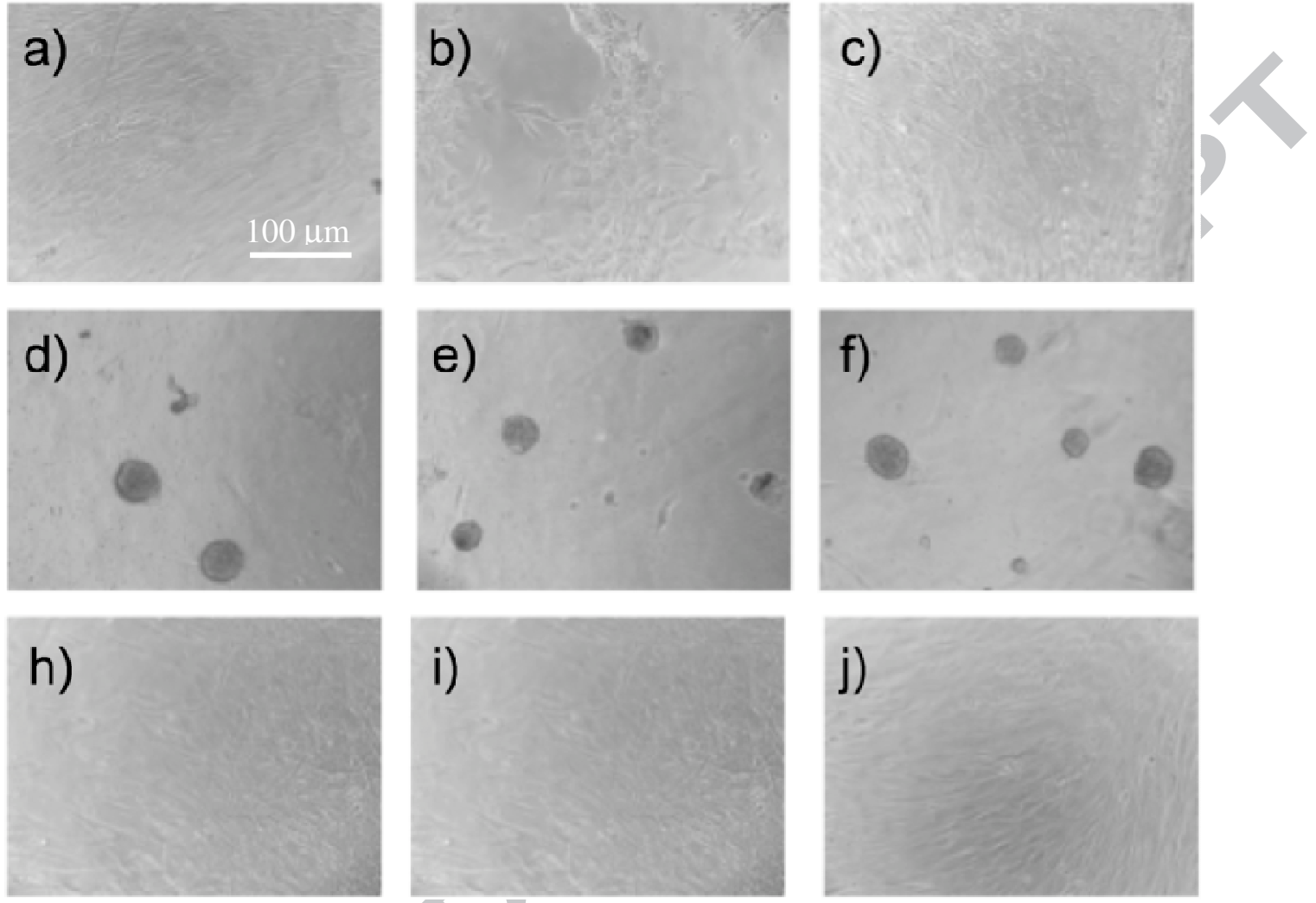
Figure 5
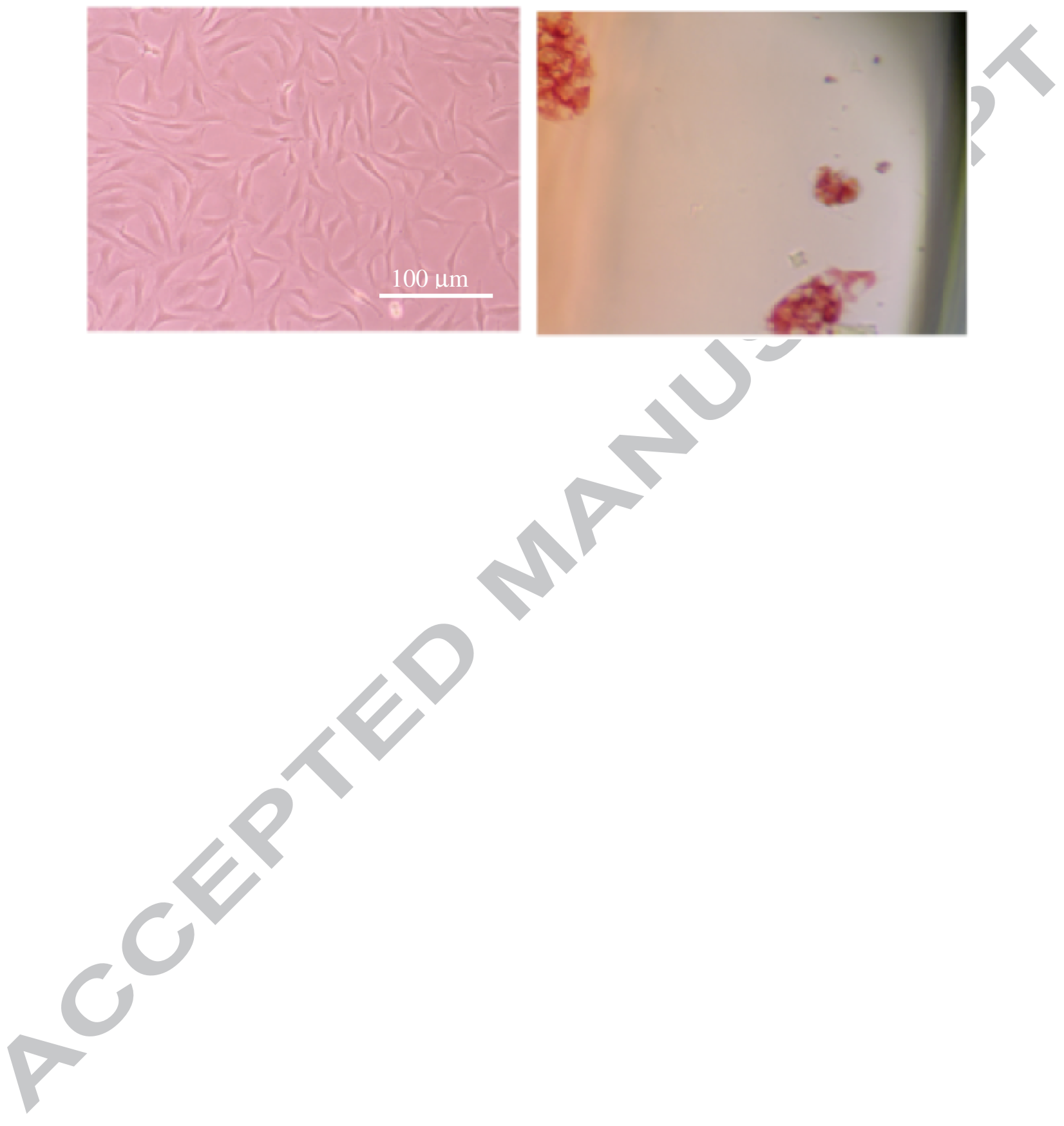